\section{DIGITAL COMMONS \\ @ UNIVERSITY OF SOUTH FLORIDA}

Journal of Practitioner Research

\title{
An analysis of preservice elementary teachers' professional noticing skills in a mathematics education setting
}

\author{
Liza Bondurant \\ Delta State University, Ibondurant@deltastate.edu \\ Lisa Poling \\ Appalachian State University, polingll@appstate.edu \\ Diana Moss \\ University of Nevada, Reno,dmoss@unr.edu
}

Follow this and additional works at: https://digitalcommons.usf.edu/jpr

Part of the Elementary Education Commons, and the Other Mathematics Commons

\section{Recommended Citation}

Bondurant, Liza; Poling, Lisa; and Moss, Diana (2020) "An analysis of preservice elementary teachers' professional noticing skills in a mathematics education setting," Journal of Practitioner Research: Vol. 5 : Iss. 2 , Article 6.

https://doi.org/10.5038/2379-9951.5.2.1156

Available at: https://digitalcommons.usf.edu/jpr/vol5/iss2/6

This Practitioner Research is brought to you for free and open access by the Open Access Journals at Digital Commons @ University of South Florida. It has been accepted for inclusion in Journal of Practitioner Research by an authorized editor of Digital Commons @ University of South Florida. For more information, please contact digitalcommons@usf.edu. 


\title{
An Analysis of Preservice Elementary Teachers' Professional Noticing in a Mathematics Education Setting
}

\begin{abstract}
Prospective elementary mathematics teachers (PTs) were asked to analyze 28 videos of cognitive interviews. The purpose of this study was to determine if experiences analyzing videos would lead to improvements in PTs' professional noticing skills. Using a coding schema that reflected three levels of understanding (periphery, transitional, and accomplished), a frequency table was constructed that allowed PTs' use and understanding of a noticing framework to be analyzed. Findings indicate that experiences analyzing videos leads to improvements in PTs' professional noticing skills.
\end{abstract}

As mathematics teacher educators (MTEs), it is our responsibility to enhance the learning experiences of those individuals entering the mathematics teaching profession and provide them with tools to augment personal content understanding, students' mathematical thinking, and instructional strategies implemented in the classroom to bolster overall mathematics inquiry. While at first this may seem to be a daunting task, the use of the Professional Noticing Framework provides a set of articulated steps that help prospective elementary teachers (PTs) make informed, in the moment, instructional decisions for teaching mathematics (Jacobs, Lamb \& Philipp, 2010). The framework progression begins with attending to the strategies the student implements to solve the problem, the second shift comes when the instructor works to interpret what the student understands related to the content, and the final piece defined by the framework encompasses the decisions related to the next instructional steps. (Jacobs, Lamb \& Philipp, 2010). In this article, we present a collaboration between three MTEs from different institutions of higher education in the United States, each representing a unique region. The MTEs' diverse experiences and perspectives enhanced this study. The MTEs engaged in practitioner research by bringing awareness to, reflecting on, and adjusting teaching (Dana \& Yendol-Hoppey, 2014). Through the use of clinically centered videos showing students working one-on-one with a teacher, PTs, enrolled in a mathematics content and methods course for elementary school teachers, were asked to identify the mathematics understanding of each student, consider instructional strategies, and make conjectures related to the authentic experiences. The research was structured in such a way that there were multiple opportunities for MTEs to reflect on and exchange ideas related to mathematics education research. PTs' use of the Professional Noticing Framework (Jacobs, Lamb \& Philipp, 2010) was analyzed using the three central tenets: 1) attend, 2) interpret, and 3) decide. The MTEs, in 
an effort to find discontinuity in PTs' use of the Professional Noticing Framework and PTs' personal content deficiencies, reviewed selected responses related to the videos and evaluated them based on previously designed coding schemes (Moss $\&$ Poling, 2019). The team chose to use the Google Drive platform (Google Docs and Google Sheets) for communication because it allowed the MTEs to access and edit shared documents.

\section{Theoretical Framework}

Despite the fact that many teacher preparation programs require PTs to spend a significant amount of time observing classroom teaching and learning, researchers cannot make specific claims about what they learn as a result of these observations (Brophy 2004). Conducting observations, without the use of the Professional Noticing Framework, may not benefit PTs, because PTs may not know what key features to focus on during the instructional episode. According to Barnhart and van Es (2015), without structured support, PTs' analyses of student knowledge typically focus on aspects of the classroom related to management rather than on students' mastery of the content. West, YendolHoppey and Jacobs (2015) posit that to transform teacher preparation programs it is critical that the tasks implemented in educational settings require PTs to observe and critique students in teaching episodes that are genuine. It is imperative that MTEs guide PTs in making instructional decisions that align with observed student understanding (Darling- Hammond \& Bransford, 2005; Davis, Petish \& Smithey, 2006; Zeichner \& Liston, 1996). A body of research has found that PTs can learn to attend, interpret, and make decisions on the basis of student thinking, skills related to analyzing teaching (Jacobs, Lamb, \& Philipp, 2010; Mitchell \& Marin, 2014; Santagata, 2011).

Through the use of video recordings as a learning tool, teaching vignettes provide an opportunity for PTs to develop their overall noticing skills (Berliner et al. 1988). Yendol-Hoppey, Jacobs, and West (2018) give voice to the idea that by developing and promoting tools that become a part of the learning process, PTs may "begin to recognize knowledge construction as "a part of' rather than 'apart from' their daily work" (p. 513). Using videos as a teaching tool saves time, money, and provides PTs the opportunity to learn new skills and to craft their practice without placing real students at risk during the learning process. Star and Strickland (2008) found that viewing videos led to significant increases in PTs' observation skills, particularly in teachers' ability to notice features of the classroom environment, mathematical content of a lesson, and teacher and student communication during a lesson. 
This research study aimed to explore the following questions:

1. In the context of a four-week online mathematics course for preservice elementary teachers, does the experience of analyzing videos of students' discussing their mathematical thinking lead to improvements in PTs' professional noticing skills?

2. How do student responses related to the framework inform MTEs instructional decisions related to methods and content for PTs enrolled in the Math Through Problem Solving course?

\section{The Instructional Activity}

The instructional activity reported in this article was implemented at a regional public university located in the south-central United States. The MTE used videos as an instructional strategy to study PTs' noticing skills. Fifteen female PTs in their second to fourth year of their studies to become elementary school teachers were a part of the study. Eleven of the PTs were White, three were Black, and one was Hispanic. Thirteen of the PTs were 20-25 years old, one was 42 years old, and one was 53 years old. PTs previously took between one and two math pedagogical content courses. PTs previous classroom experience includes 30 hours of focused observations in the areas of diversity, classroom management, and teaching strategies in a Survey of Education with Field Experiences course. They also have completed 10 hours of focused observations in diverse classroom settings related to classroom management along with small group teaching assignments in a Classroom Management course.

PTs were enrolled in an online course, Math Through Problem Solving. The study took place during Summer Session II. Therefore, the content of the course, which is typically taught over the course of a 15-week semester, was compressed into four weeks. The course focused on the following units: Number Theory, Fractions, Decimals, and Integers. One week was spent on each unit. In each unit, the first assignment was for the PTs to read the sections in the unit. The information from the book was also summarized in power points on a Supplemental Resources Page. PTs were required to take a Readiness Assurance Test (RAT) which focused on the weekly reading. The PTs completed the unit homework assignments. Lastly, after completing a practice test, the PTs took a unit test. This sequence of assignments was repeated by PTs in each of the four units. Before the end of the course PTs were required to "pass", $80 \%$ or better, a Rational Numbers proficiency test that they have up to three attempts to pass. At the end of Unit 4, the PTs took a final exam. Throughout the week PTs were asked to work on their cognitive interview video analysis assignment worth $10 \%$ of PTs' final grade. 
The MTE developed the Cognitive Interview Video Analysis assignment to capture PTs' professional noticing skills. Over the course of the class the PTs were asked to watch and analyze 28 videos of cognitive interviews. Each cognitive interview is a brief (less than 5 minute) one-on-one interview with a $\mathrm{K}$ 5 student who is asked to solve a problem and is provided with task-appropriate manipulatives, paper, and writing utensils. The cognitive interviews were focused on Number Theory (five videos), Fractions (eleven videos), Decimals (six videos), and Integers (five videos). The MTEs decided to focus their study on PTs' analysis of three videos, all focused on the concept of ordering, but completed across the span of the course. More specifically, the first video was focused on ordering fractions, the second video on ordering decimals, and the third video on ordering integers.

Before engaging in professional noticing, the PTs read the article A New Lens on Teaching: Learning to Notice (Sherin \& van Es, 2003). In this article, the authors provide examples of how in-service teachers reflect on their teaching through noticing. Reading this article helps the PTs realize that noticing will help them make in-the-moment decisions and that there are a variety of ways to use noticing in their future classrooms.

The prompts that the interviewer asked the children in these three videos can be found in Figure 1.

\section{Figure 1}

Image of the Tasks Presented to Students

\begin{tabular}{|c|}
\hline 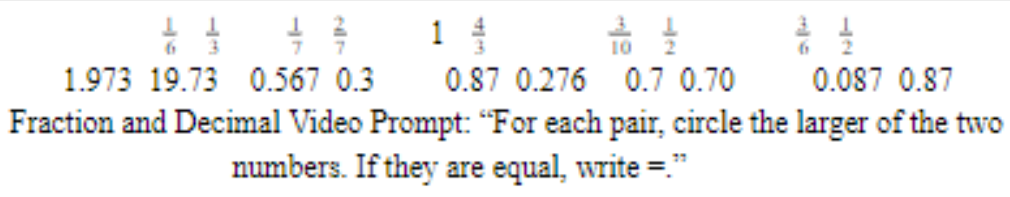 \\
\hline $\begin{array}{l}\qquad \begin{array}{llllllll}|6|-5 \mid & -7 & 2 & -1 & 11 & 0 & -13\end{array} \\
\text { Integer Prompt: Order the numbers from least to greatest }\end{array}$ \\
\hline
\end{tabular}

For each video, the assignment directions were:

Post one (1) initial post where you answer each question below. Grading is based on effort (thoughtful and thoroughly explained answers) not accuracy. You are encouraged to read your peers' posts (you must make your initial post before being able to read others' posts) and post replies based on your reactions. Embedded in the book you will find the following video (there is a 
movie icon in the reading). Watch the video and then respond to each of the following prompts.

\author{
Attending: \\ 1. What did the student do? \\ 2. What strategies did the student use? \\ Interpreting: \\ 3. What does this mean about the student's understandings or \\ misconceptions of the mathematics? \\ Deciding: \\ 4. Based on what you attended to and interpreted, what are the best steps to \\ take next with this student? \\ 5. What questions would you ask this student?
}

The MTE structured the assignment as a discussion for three main reasons. For one, since the course was an online class, there are no opportunities to discuss the videos face to face. Secondly, the instructor wanted to be able to provide PTs with feedback about the expectations of the assignment as well as feedback and guidance for meeting those expectations. Finally, the MTE believed that PTs could benefit from seeing each other's responses and the MTE's feedback on their responses.

\title{
Methodology
}

This paper reports on the integrated findings of an exploratory sequential mixed methods research design (Figure 2).

\section{Figure 2}

Exploratory Sequential Design (Creswell \& Plano Clark, 2011)

In sequential exploratory design, qualitative data is first collected and analyzed, and themes are used to drive the development of a quantitative instrument to further explore the research problem (Creswell \& Plano Clark, 2011). As a result of this design, three stages of analyses were conducted: after the initial qualitative phase, after the secondary quantitative phase, and at the integration phase that connects the two strands of data and extends the initial qualitative exploratory findings (Creswell \& Plano Clark, 2011). In this paper the authors share the results of the final integration phase of the research. 
The first goal of the coding process was to establish a standard exemplar response to the assignment for each video. To accomplish this goal, we, the team of three MTEs, each completed the Cognitive Interview Analysis assignment individually. Next, we met to discuss any discrepancies in the exemplar responses. We resolved any differences that existed and merged responses to create a standard exemplar response for each video. This task provided us with a standard exemplar to reference during coding. It also provided us with a thorough understanding of the content of the videos.

Next, we decided to use the coding scheme developed by Moss and Poling (2019). The coding scheme is described in Figure 3.

Figure 3

Coding Scheme for Professional Noticing

\begin{tabular}{|l|l|}
\hline Noticing Level & Description \\
\hline Periphery & Made general impressions (e.g. "Student understands the questions.") \\
\hline Transitional & $\begin{array}{l}\text { Highlighted noteworthy events, general impressions, but included why they } \\
\text { believed something occurred (e.g. "The student used logic to reason through } \\
\text { the problem." }\end{array}$ \\
\hline Accomplished & $\begin{array}{l}\text { Used evidence to elaborate on student understanding, made connections } \\
\text { between the work and the next steps. }\end{array}$ \\
\hline
\end{tabular}

To analyze PSTs' responses, we used open coding (Corbin \& Strauss, 2014) to determine the noticing level for each attending, interpreting, and deciding prompt in the Cognitive Interview Analysis assignment.

Prior to coding, all PTs names were removed and the responses were randomized in the spreadsheet to avoid any potential coding biases. The MTEs calibrated coding by discussing our inferences and interpretations of one PT's responses to each of the five items. Subsequently, each MTE independently double-coded all PTs' responses for two of the three videos, in a blinded format, to ensure the data from each video was analyzed by two MTEs. The percent agreement for the two raters across all items was $75 \%$, suggesting substantial inter-rater agreement. Having computed a satisfactory percent agreement, we reconciled our coding through discussion of the data and the Professional Noticing Framework coding scheme (Figure 3). 


\section{Findings: PTs' Professional Noticing Skills}

Through the lens of the Professional Noticing Framework (Attend, Interpret, and Decide), the results of the study show patterns of growth related to the noticing levels of periphery, transitional, and accomplished. Once PTs' responses were coded using the scheme (Figure 3), the results of the noticing levels were analyzed for each of the three noticing assignments in the given semester (Comparing Fractions, Comparing Decimal Numbers, and Ordering Integers). The bar graph in Figure 4 shows the overall frequency of each response coded as periphery, transitional, and accomplished within each noticing assignment.

\section{Assignment}

Table 1 provides overall percentages of responses coded as periphery, transitional, and accomplished within each noticing assignment.

\section{Table 1}

\section{Overall Percentages of Periphery, Transitional, and Accomplished}

Assignment Periphery Transitional Accomplished

\begin{tabular}{llll}
\hline 6.1C: Comparing Fractions & 0.83 & 0.15 & 0.015 \\
7.1A: Comparing Decimal & 0.66 & 0.29 & 0.046 \\
8.2A: Ordering Integers & 0.69 & 0.2 & 0.107 \\
\hline
\end{tabular}

The percentage of responses coded as "periphery" decreased from $83 \%$ to $69 \%$, whereas "transitional" increased from $15 \%$ to $20 \%$ "accomplished" increased from $1.5 \%$ to $10.7 \%$, indicating that as the semester progressed, PTs' responses moved toward a transitional and accomplished level of interpreting student thinking. As seen in Figure 4, 54 of the PTs' responses were at a "periphery" level on the first assignment (Comparing Fractions) and only 1 PT response was at the "accomplished level on the first assignment. 
Figure 4

Overall Frequency of Periphery, Transitional, and Accomplished on each

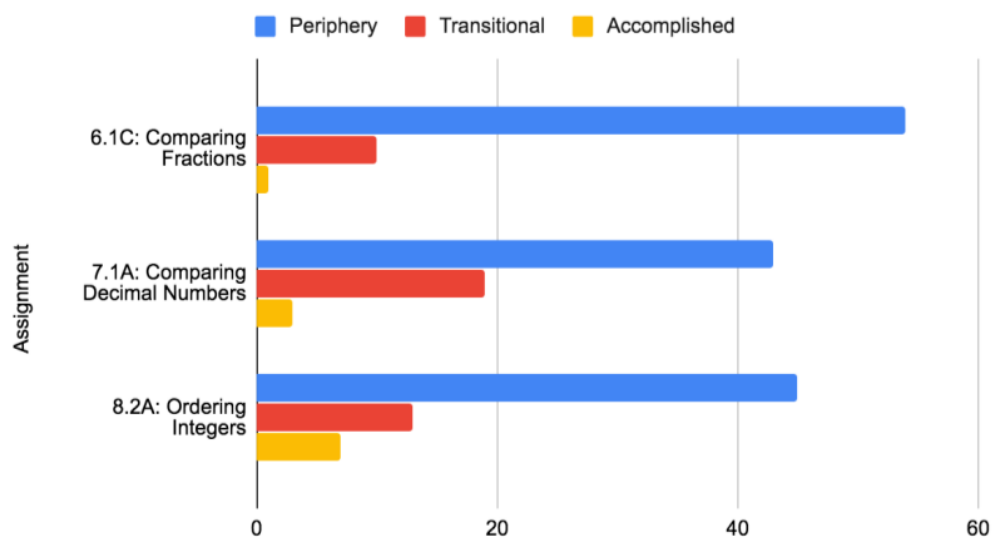

However, 45 PT responses were at the "periphery" level on the last assignment (Ordering Integers) and 7 PT responses were at the "accomplished" level on the last assignment.

These results indicate that the PTs have little experience with examining student mathematical thinking as seen on videos at the onset of this course. But, with practice, PTs' abilities to professionally notice improved as the course progressed. Based on experience and coursework, this seems to be a natural consequence of interacting with the ideas related to the framework. As shown in Figure 5, there is an overall increase of transitional responses in two of the three categories when considering Activity 7.1A. 
Figure 5

Percent Periphery, Transitional, Accomplished by Video
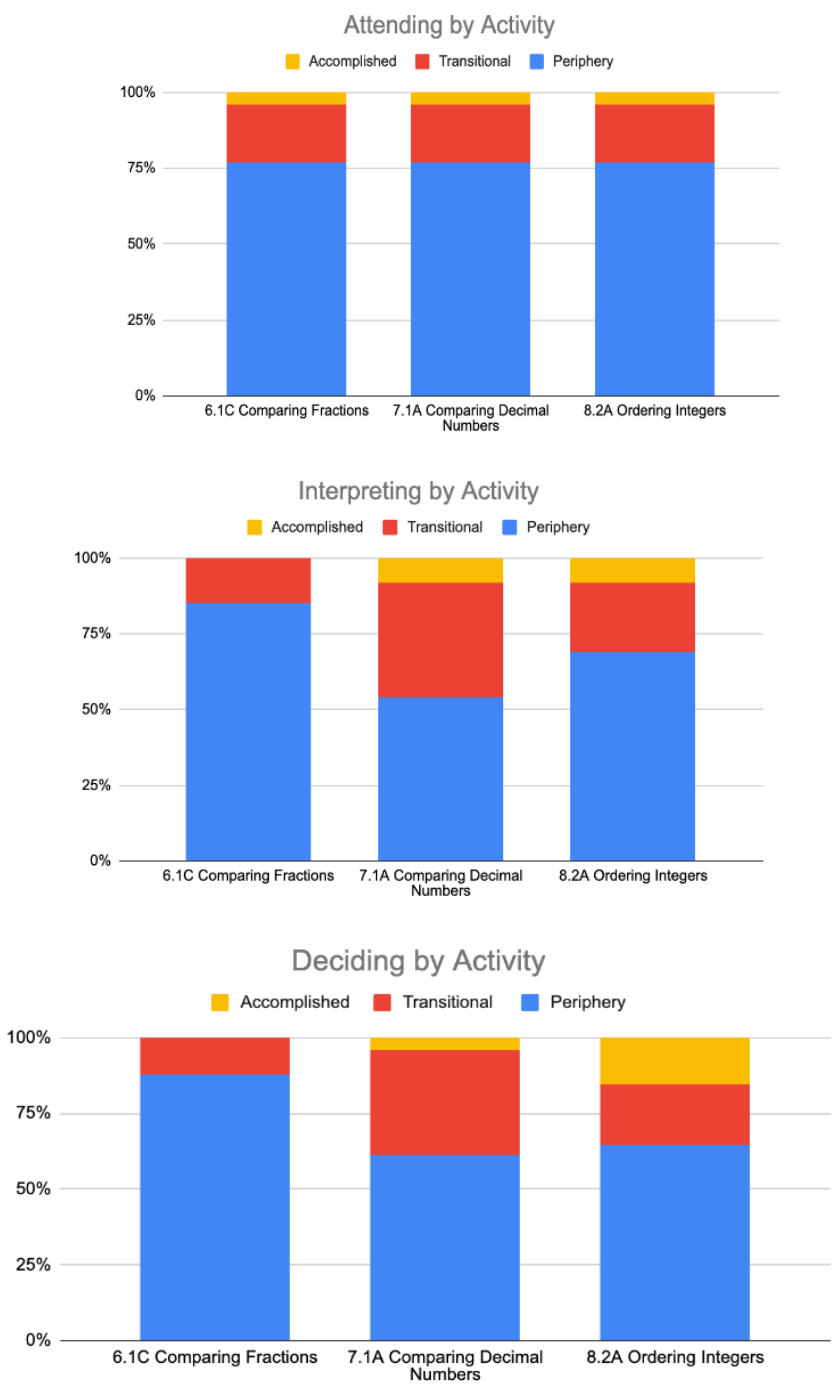

The attending percentage remained constant between Activity 6.1C and 7.1A. There is a slight decrease in transitional responses related to activity $8.2 \mathrm{~A}$ but it is still down trending related to the introductory activity.

For example, one PT's response to the deciding piece of the framework changed over time. In the first assignment, the student offered the following 
suggestion, "And for both students I would ask the same questions the instructor did, and I would ask for more examples and review questions". Then, on a later video, the PT's level of sophistication changed and their response became, "What strategies are you using?", "How did you come up with that strategy?", "How did you figure out the answer?". As you can see, the later response is focused on conceptual understanding and is student-centered.

Three of the fifteen PTs did not complete all three assignments (chapters 6, 7, and 8). Therefore, their data were removed from the participant level analyses, resulting in $n=12$. At the participant level, we (the MTEs) counted how many of the questions (out of the five questions) each PT answered at each noticing level for the three (comparing fractions, decimals, and integers) assignments. Next, we calculated the frequency and percent changes in the number of questions each PT answered at each noticing level from the first to the second, second to third, and first to third assignments. Finally, we found the average frequency and percent changes for all PTs.

We found a decrease in PTs' performance at the peripheral level over the span of the course. All twelve PTs answered 49 questions at the peripheral level on the assignment 6.1C. On the assignment 7.1A, all twelve PTs answered 43 questions at the peripheral level. All twelve PTs answered 40 questions at the transitional level on the assignment 8.2A. The average number of questions that PTs answered at the peripheral level decreased by a frequency of $0.5,0.25$, and 0.75 from the first to the second assignment, second to the third, and the first to the third assignments, respectively. The average number of questions the PTs answered at the peripheral level decreased by $13.19,0.69$, and 19.44 percent from the first to the second assignment, second to the third, and the first to the third assignments, respectively.

We found an increase in PTs' performance at the transitional level from beginning to middle and beginning to end of the course, but a slight decrease at the transitional level from the middle to the end of the course. Nine of the twelve PTs answered ten questions at the transitional level on the first assignment (6.1C). On the second assignment (7.1A), eight PTs answered fifteen questions at the transitional level. Seven PTs answered fourteen questions at the transitional level on the third assignment (8.2A). The average number of questions that PTs answered at the transitional level changed by a frequency of $0.41,-0.17$, and 0.25 from the first to the second assignment, second to the third, and the first to the third assignments, respectively. The average number of questions that PTs answered at the transitional level changed by $22.73,-2.27$, and 4.55 percent from 
the first to the second assignment, second to the third, and the first to the third assignments, respectively.

We found an increase in PTs' performance at the accomplished level during the course. Only one PT answered one question at the accomplished level on the first assignment. On the second assignment two PTs each answered one question at the accomplished level. Five PTs answered six questions at the accomplished level on the third assignment. The average number of questions that PTs answered at the accomplished level increased by a frequency of $0.08,0.33$, and 0.42 from the first to the second assignment, second to the third, and the first to the third assignments, respectively. In most cases, the percent change could not be calculated because zero PTs initially answered at the accomplished level (causing a dividing by zero error in the percent change calculations).

\section{Findings: Instructional Adjustments}

Since conducting the study reported on in this article, the MTE that teaches the Math Through Problem Solving course has continued to implement the Instructional Activity with the PTs. In the subsequent Fall semester of the course, the MTEs reflected on the lessons learned from the initial implementation and made several alterations to the Instructional Activity. To help PTs understand the expectations of the assignment, the MTE provided the PTs with an exemplar and a rubric. The exemplar was collaboratively developed by the MTEs during the coding process. The exemplar illuminates expert professional noticing. The rubric has helped PTs develop a better understanding of the gradations of quality for each noticing prompt and has led to more PTs reaching the target level.

Additionally, the MTE changed the activity from a public online discussion to a confidential online submission assignment. This change was made to prevent PTs from simply rewording others' responses and possibly not watching the cognitive interview videos. Moreover, the MTE provided the PTs with a spreadsheet template with the video titles listed in the rows and the prompts listed in the columns. This measure helped PTs keep their work organized and prevented them from skipping a response or associating a response with the wrong video or prompt. A discussion board remains dedicated to this activity, but is focused on resolving any misunderstandings that arise as the PTs work to complete the activity. During the Math Through Problem Solving class, the MTE continued to introduce the activity by watching one cognitive interview video and discussing responses to the prompts with the PTs. Finally, once the assignments are submitted and graded the MTE debriefs common areas the PTs' excelled on as well as areas in need of improvement. Each of the aforementioned measures has contributed to higher quality work and preliminary results suggest that the 
adjustments made to the course and to the instructional activity have led PTs to provide more thoughtful and thorough responses.

\section{Conclusion and Implications}

This practitioner research study, framed by research on noticing, was used to assess the development of PTs' use and understanding of noticing. The results are promising that the experience of analyzing videos of students' discussing their mathematical thinking is a viable strategy for supporting PTs' professional noticing skills. Although many PTs' professional noticing skills improved, some PTs' skills did not show an overall increase, and few PTs reached the accomplished level. More research is needed to determine how to scaffold all PTs' skill development to the accomplished level. Analysis of the instructional activity indicates that prior to this course PTs have had little experience describing students' work, interpreting students' understandings, and then deciding how to proceed. PTs' initial interpretations seemed to rely on their own content understanding related to the task and limited the PTs in their ability to apply appropriate strategies to promote conceptual understanding for students. These results indicate the need for MTEs to spend more time reflecting on and discussing implications for teaching. Engagement in this work allowed us to see the PTs' reasoning so that we, mathematics educators, can improve our practice and our PTs' professional noticing skills. 


\section{References}

Barnhart, T., \& van Es, E. (2015). Studying teacher noticing: Examining the relationship among pre-service science teachers/ ability to attend, analyze and respond to student thinking. Teaching and Teacher Education, 45, 83-93.

Berliner, D. C., Stein, P., Sabers, D. S., Clarridge, P. B., Cushing, K. S., \& Pinnegar, S. (1988). Implications of research on pedagogical expertise and experience in mathematics teaching. In D. A. Grouws \& T. J. Cooney (Eds.), Perspectives on research on effective mathematics teaching (pp. 67-95). Reston, VA: National Council of Teachers of Mathematics.

Brophy, J. (Ed.) (2004). Using video in teacher education. Amsterdam: Elsevier Ltd.

Burns, R. W., Yendol-Hoppey, D., \& Jacobs, J., (2015). High-quality teaching requires collaboration: How partnerships can create a true continuum of professional learning for educators. The Educational Forum, 79, 53-67.

Corbin, J., \& Strauss, A. (2014). Basics of qualitative research: Techniques and procedures for developing grounded theory (4th ed.). Thousand Oaks, CA: Sage.

Creswell, J. W., \& Plano Clark, V.L. (2011). Designing and Conducting Mixed Methods Research. SAGE Publications. 2nd ed. Thousand Oaks, CA: SAGE Publications.

Dana, D.F., \& Yendol-Hoppy, D. (2014). The reflective educator's guide to classroom research: Learning to teach and teaching to learn through practitioner inquiry (3rd ed.). Thousand Oakes, CA: Corwin.

Darling-Hammond, L. \& Bransford, J. (2005). Preparing teachers for a changing world: What teachers should know and be able to do. San Francisco, CA: Jossey-Bass.

Davis, E., Petish, D. \& Smithey, J. (2006). Challenges new science teachers face. Review of Educational Research, 76(4). 607-651.

Jacobs, V. R., Lamb, L. L. C., \& Philipp, R. A. (2010). Professional noticing of children's mathematical thinking. Journal for Research in Mathematics Education, 41, 169-202.

Mitchell, R. N., \& Marin, K. A. (2014). Examining the use of a structured analysis framework to support prospective teacher noticing. Journal of Mathematics Teacher Education, 18, 551-575.

Moss, D., \& Poling, L. (2019). Using a noticing framework in a mathematics methods course. Journal on Empowering Teaching Excellence, 3(1), 1-16.

Santagata, R. (2011). From teacher noticing to a framework for analyzing and improving classroom lessons. In Sherin, M. G., Jacobs, V. R., \& Philipp, R. 
A. (Eds.), Mathematics teacher noticing: Seeing through teachers' eyes (pp. 152-168). New York, NY: Routledge.

Sherin, M, \& van Es, E. (2003). A New Lens on Teaching: Learning to Notice. Mathematics Teaching in the Middle School, (2), 92.

Star, J., \& Strickland, S. (2008). Learning to observe: Using video to improve preservice mathematics teachers' ability to notice. Journal of Mathematics Teacher Education, 11, 107-125.

Yedol-Hoppey, D., Jacobs, J., \& Burns, R. W. (2018). Improving teacher practice-based knowledge. In Zepeda, S.J. \& Ponticell, J.A. (Eds.) The Wiley handbook of education supervision (pp. 512-532). Hoboken, NJ: Wiley.

Zeichner, K. \& Liston, D. (1996). Reflective teaching: An introduction. Mahwah, NJ: Lawrence Erlbaum Associates. 
Bondurant et al:: An analysis of preservice elementary teachers' professional noticing skills in a mathematics education setting 
Journal of Practitioner Research, Vol. 5 [2020], Iss. 2, Art. 6

https://digitalcommons.usf.edu/jpr/vol5/iss2/6

DOI: $<p>$ https://doi.org/10.5038/2379-9951.5.2.1156</p> 